since $C$. burnetti is a highly resistant microorganism; second, it enters the host cells by a passive mechanism unlike true rickettsiae and a rash almost never occurs in acute $Q$ fever; third, patients lack cross-reacting antibodies to proteus $\mathbf{X}$ strains (Weil-Felix reaction). ${ }^{1}$ Therefore, rickettsaemia often follows a proliferation of microorganisms in the lungs and a self-limited febrile illness with or without pneumonia is the most common form of $\mathrm{Q}$ fever ${ }^{1,6}$ Nevertheless, $\mathrm{Q}$ fever can present as an acute hepatitis without any pulmonary manifestations ${ }^{6}$ and our report demon- strates that it can also present as isolated lymphocytic meningitis. A lumbar puncture is not usually performed on patients with $Q$ fever. However, the common occurrence of severe headache noted in $65-90 \%$ of the patients, ${ }^{6}$ as well as the biology of the infection ${ }^{1}$ suggest that lymphocytic meningitis in $\mathbf{Q}$ fever may occur much more frequently than realized, and in fact, $C$. burnetti has been isolated from the CSF of such patients. ${ }^{7}$ Serology for rickettsial diseases including $C$. burnetti should always be performed in unexplained lymphocytic meningitis.

\title{
References
}

1. Saah, A.J. Rickettsiosis. In: Principles and Practice of Infectious Diseases (Mandell, G.L., Douglas, R.G.Jr, Benett, J.E. eds.), Churchill Livingstone, New York, 1990, pp. 1463-1483.

2. Kirk, J.L., Fine, D.P., Sexton, D.J. \& Muchmore, H.G. Rocky Mountain spotted fever. A clinical review based on 48 confirmed cases, 1943-1986. Medicine 1990, 69: 35-45.

3. Silpapojakul, K., Ukkachoke, C., Krisanapan, S. \& Silpapojakul, K. Rickettsial meningitis and encephalitis. Arch Intern Med 1991, 151: 1753-1757.

4. Miller, J.Q. \& Price, T.R. The nervous system in Rocky Mountain spotted fever. Neurology 1972, 22: 561-566.

5. Linnemann, C.C., Pretzman, C.I. \& Peterson, E.D. Acute febrile cerebrovasculitis. A non-spotted fever group rickettsial disease. Arch Intern Med 1989, 149: 1682-1684.

6. Sawyer, L.A., Fishbein, D.B. \& McDade, J.E. Q fever: current concepts. Rev Infect Dis 1987, 9: 935-946.

7. Robins, R.C. $Q$ fever in the Mediterranean area: report of its occurrence in allied troops. Am J Hyg 1946, 44: 51-71.

\section{Pseudotumour cerebri associated with arteriovenous malformations}

\author{
O.C. Cockerell, H.M. Lai and R.W. Ross-Rusșell \\ Department of Neurology, St Thomas' Hospital, London SE1 7EH, UK
}

\begin{abstract}
Summary: The association of intracranial hypertension and arteriovenous malformations is described in two patients. Both patients had the typical clinical features of pseudotumour cerebri and were found to have intracranial arteriovenous malformations on arteriography. The mechanism of raised intracranial pressure in patients with arteriovenous malformations is discussed.
\end{abstract}

\section{Introduction}

The recognition of a syndrome of raised intracranial pressure without ventricular distension dates from $1897 .{ }^{1}$ The number of different putative causes and associations has expanded over the years. $^{2,3}$ It is known that pseudotumour cerebri may occur with no identifiable cause, or secondary

Correspondence: O.C. Cockerell, M.B., B.S., National Society of Epilepsy, Chalfont St Peter, Bucks SL9 0RJ, UK.

Accepted: 18 December 1992 to various specific disorders. ${ }^{4}$ The common factor in producing the raised pressure is a disturbance of the normal dynamics of cerebrospinal fluid production and absorptions..$^{5-7}$ By definition, the term pseudotumour cerebri excludes patients with raised intacranial pressure secondary to space occupying lesions producing a mass effect, or patients with ventricular distension. ${ }^{8}$ However, there is a small group of patients with pseudotumour cerebri who do have a focal vascular lesion, usually involving the venous sinuses, producing raised intracranial 
pressure by impairing cerebrospinal fluid (CSF) outflow. ${ }^{4}$ The recognition of arteriovenous malformations as a cause of pseudotumour cerebri would have been expected to increase with the development of magnetic resonance scanning. However, there are only four cases of pseudotumour cerebri in association with arteriovenous malformations in the literature in whom other causes of pseudotumour cerebri including venous sinus occlusion, have been excluded. ${ }^{4,9-11}$

We present two further patients who have pseudotumour cerebri secondary to an arteriovenous malformation (AVM) and review the possible mechanism of raised intracranial pressure.

\section{Case histories}

\section{Case 1}

A 35 year old Caucasian female presented with a 2 month history of headaches. These were constant with no relieving or exacerbating factors. She also had spontaneous brief episodes of visual blurring affecting both eyes, together or separately. There was no relevant past medical history. She was on no medications. On examination her visual acuities were $6 / 6$ in both eyes unaided. Her visual fields demonstrated enlargement of the blind spots on Goldman perimentry. There was bilateral papilloedema. She had a bruit over the left cranium. The rest of the neurological and systemic examination was normal.

A biochemical and haematological profile was normal. A computed tomographic brain scan showed a cerebral arteriovenous malformation in the left frontoparietal lobe. An angiogram (Figure 1) demonstrated this to be a small vessel arteriovenous malformation supplied by cortical branches of the left anterior and middle cerebral arteries, with drainage mainly into the superior sagittal sinus. There was no evidence of sinus occlusion. A lumbar puncture was performed with a CSF pressure of $28 \mathrm{~cm}$. The CSF constituents were normal.

An embolization procedure was carried out. A branch of the left middle cerebral artery was catheterized and injected with histacryl. Following this the patients had a dramatic resolution of her headaches and visual blurring, with reduction of her optic disc swelling.

\section{Case 2}

A 65 year old Indian man presented with a 3 month history of poor vision. He had had non-specific tension headaches for many years. He also complained of a pulsating noise in his head. He had a past history of hypertensive nephropathy con-

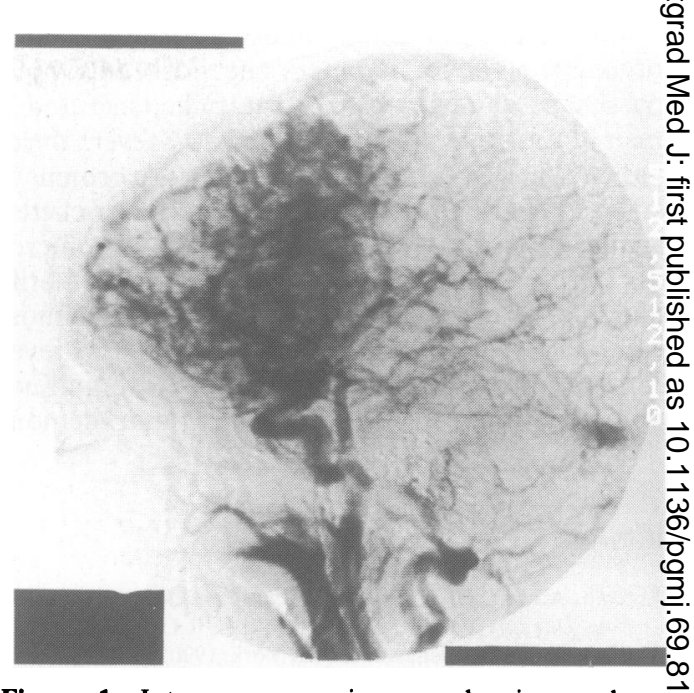

Figure 1 Intravenous angiogram showing a large $\vec{A}$ arteriovenous malformation supplied by branches of the left anterior and middle cerebral arteries with drainage into the distended sagittal sinus.

trolled with continuous ambulatory peritoneal dialysis for 8 years. His medications consisted of ${ }_{-}$ alphacalcidol and calcium carbonate. On examing-e tion his visual acuities were $6 / 6$ bilaterally unaide.$\omega$ His fields were constricted to Goldman perimen with enlarged blind spots. Both his optic discs were chronically swollen. There was a right cranial bruit.⿳亠二口犬 The rest of the examination was normal apart from his indwelling peritoneal catheter. His blood pres- $\frac{\mathbb{Q}}{\Omega}$ sure was $120 / 85 \mathrm{mmHg}$.

Investigations showed a mild anaemia haemo-⿳亠丷厂 globin $(9.5 \mathrm{~g} / \mathrm{dl})$ with normal haematinics. Blood? urea and creatinine were $14.2 \mathrm{mmol} / 1$ ando $190 \mu \mathrm{mol} / 1$ respectively. Serum calcium and phosphate were normal. Computed tomographic brain 3 . scan was normal. A lumbar puncture showed and opening pressure of $34 \mathrm{~cm}$ of water and normal constituents. An angiogram was performed. Thiso̊ showed an intracranial arteriovenous malformation between the right occipital artery and a duralo sinus.

The AVM was embolized with histacryl. Immediately following this there was relief of the patient's pulsating noise. Later his papilloedema o improved and his visual fields enlarged.

\section{Discussion}

Raised intracranial pressure in patients with $\stackrel{\mathcal{Q}}{?}$ arteriovenous malformations is usually secondary 0 to subarachnoid haemorrhage with consequent communicating hydrocephalus and ventriculo- $\stackrel{\mathbb{D}}{\mathbb{Q}}$ megaly. The high flow rates through the arterio- $\stackrel{\mathbb{\mathbb { D }}}{\varrho}$ 
venous malformation may also provoke sagittal sinus thrombosis and then produce psuedotumour by interfering with CSF absorption. ${ }^{12,13}$ In our patients neither of these factors was operating. Other causes of raised intracranial pressure such as cerebral oedema, mass effect or ventricular obstruction were also absent.

The occurrence of raised intracranial pressure in patients with an arteriovenous malformation is rarely mentioned in the literature. In a review of 545 patients with arteriovenous malformations not one patient is mentioned with papilloedema. ${ }^{14}$ Out of 110 patients reported by Paterson, ${ }^{15} 17$ had papilloedema, 14 secondary to subarachnoid haemorrhage, one from non-communicating hydrocephalus, and the other cause was not specified. In a description of arteriovenous malformations involving the transverse sinus, $24 \%$ were described as having papilloedema. ${ }^{16}$ Unfortunately there was no information provided on the CSF pressure, presence of hydrocephalus, or association with subarachnoid haemorrhage. In another report of 16 patients, also with dural arteriovenous malformations, ${ }^{17}$ two had papilloedema, this was secondary to subarachnoid bleeding in one and cavernous sinus distension in the other. There are more reports of raised intracranial pressure secondary to anteriovenous malformations in infants than in adults. ${ }^{18-23}$ However, ventriculomegaly is present in infants. It has been suggested that it is the ability or inability of the cranial vault to expand that differentiates these two groups. ${ }^{24}$ Cronquist speculated that the mechanism of raised intracranial pressure was that by shunting blood into the sagittal sinus the sinus pressure was increased and CSF absorption was disturbed. ${ }^{19}$ One infant was described with an extracranial AVM which shunted blood into the transverse sinus causing raised CSF pressure and hydrocephalus. ${ }^{23}$ In adults the same mechanism may operate to produce pseudotumour cerebri in patients with arterio-

\section{References}

1. Quincke, $H$. Ueber Meningitis Serosa und verwandte Zustande. Dt Z Heilk 1897, 9: 149-168.

2. Weisberg, L.A. Benign intracranial hypertension. Medicine 1975, 54: 197-207.

3. Johnstone, I. \& Paterson, A. Benign intracranial hypertension. I. Brain 1974, 97: 289-300.

4. Johnstone, I., Hawke, S. Halmagyi, M. \& Teo, C. The pseudotumour syndrome. Arch Neurol 1991, 48, 740-747.

5. Johnstone, I. \& Paterson, A. Benign intracranial hypertension. II. Brain 1974, 97: 301-312.

6. Davson, H., Domer, F.R. \& Hollingsworth, J.R. The mechanism of drainage of the cerebrospinal fluid. Brain 1973, 96: 329-336.

7. Cutler, R.W.P., Page, I., Gallich, J. \& Watters, G.V. Formation of cerebrospinal fluid in man. Brain 1968, 91: 707-720.

8. Nonne, M. Uber Falle vom Symptomkomplex 'Tumour cerebri' mit Ausgang in Heilling (pseudotumour cerebri): uber letal verlaufene Falle von 'Pseudotumour cerebri' mit Sektionsbefund. Disch Z Nerv 1904, 27: 169-216. venous malformations. The increased sagittal sinus pressure is counterbalanced by an increase in CSF pressure to maintain the CSF-sagittal sinus pressure gradient. ${ }^{5,25,26}$ In one patient with an arteriovenous malformation and pseudotumour cerebri sagittal sinus pressure and CSF pressure were measured during removal of the arteriovenous malformation which was shunting blood into the transverse sinus. ${ }^{9}$ They found that the sagittal sinus pressure was considerably raised but consistently lower than CSF pressure.

The site of the arteriovenous malformation seems to have no bearing on whether pseudotumour cerebri is produced. Of the four cases in the literature, three were in the cerebral parenchyma $^{4,10,11}$ and the other was dural. ${ }^{9}$ All shunted blood into the sagittal sinus although the dural arteriovenous malformation ${ }^{9}$ was via the transverse sinus. The second of our cases was a dural AVM the other an intracerebral AVM. Presumably it is the pressure in the sagittal sinus that is the critical factor rather than the size or position of the AVM. The larger and more numerous the arterial component of the AVM, the higher the pressure transmitted to the draining veins. This cannot be assessed by angiography, although in the first case the degree of distension of the sagittal sinus gives some indication of raised venous pressure. The prognosis is favourable for the pseudotumour cerebri syndrome if the AVM can be treated. One patient reported by Lamas $^{9}$ underwent selective embolization of the ateriovenous malformation with resolution of the raised pressure altogether. Another was treated by a lumbar peritoneal shunt with success. ${ }^{11}$ No treatment details are available from the other two cases. Both our patients had a useful response to embolization. This method not only cures the pseudotumour cerebri but also reduces the risk of subsequent bleeding from the arteriovenous malformation which is the major cause of morbidity and mortality. ${ }^{14}$

9. Lamas, E., Lobarto, R.D., Esparza, J. \& Escudero, L. Dural posterior fossa AVM producing raised sagittal sinus pressure. $J$ Neurosurg 1977, 46: 804-810.

10. D'Avella, D., Greenberg, R., Mingrino, S., Scanarini, M. \& Pardatscher, K. Alterations in ventricular size caused by sagittal sinus pathology in man. J. Neurosurg 1980, 53: 656-661.

11. Weisberg, L.A., Pierce, J.F. \& Jabbari, B. Intracranial hypertension resulting from a cerebrovascular malformation. South Med J 1977, 70: 624-626.

12. Convers, P., Michel, D., Brunon, J. \& Sindou, M. Fistules arterioveineuses durales de la fosse cerbrale posterieure et thrombose du sinus laterale. Neurochirurgie 1986, 32: 495-500.

13. Enevoldson, T.P. \& Ross-Russell, R.W. Cerebral venous thrombosis: new causes for an old syndrome. Quart $\mathrm{J}$ Med 1990, 284: $1255-1275$. 
14. Perret, G. \& Nishoka, H. Report on the cooperative study of intracranial aneurysms and subarachnoid haemorrhage VI. Arteriovenous malformations. $J$ Neurosurg 1966, 32: 467-489.

15. Paterson, J.H. \& McKissock, W. A clinical survey of intacranial angiomas with special reference to their mode of progression and surgical treatment: a report of 110 cases. Brain 1956, 79: 223-266.

16. Obrador, S., Soto, M. \& Sivela, J. Clinical syndromes of arteriovenous malformations of the transverse-sigmoid sinus. J Neurol Neurosurg Psychiatry 1975, 38: 436-451.

17. Aminoff, M.J. Vascular anomalies of the intracranial dura mater. Brain 1973, 96: 601-612.

18. Gibson, J.B., Taylor, A.R. \& Richardson, A.E. Congenital arteriovenous fistula with an aneurysm of the great cerebral vein and hydrocephalus. J Neurol Neurosurg Psychiat 1959, 22: 224-228.

19. Cronquist, S. Granholm, L. \& Lundstrom, N. Hydrocephalus and congestive cardiac failure caused by intracranial arteriovenous malformations in infants. $J$ Neurosurg 1972, 36: 249-254.
20. Askenasy, H.M., Herzberger, E.E. \& Wijsenbeck, H.S Hydrocephalus with vascular malformations of the brain $\bar{z}$ Neurology 1953, 3: 213-220.

21. Davidoff, L.M. \& Epstein, B.S. The Abnormal Pneumo encephalogram. Lea \& Febiger, Philadelphia, 1950, p. 506. $\subseteq$

22. Russell, D.S. \& Nevin, S. Aneurysm of the great vein of Galen causing internal hydrocephalus. J Path Bact 1940, 51: 375. की

23. Lange, S.A. \& Vleiger, M. de. Hydrocephalus associated witho raised venous pressure. Develop Med Child Neurol 1970, $12 \bar{\sigma}$ (Suppl 22): 28-32.

24. Rosman, N.P. \& Shands, K.N. Hydrocephalus caused by increased intracranial venous pressure: a clinicopathological study. Ann Neurol 1978, 3: 445-450.

25. Bradley, K.C. Cerebrospinal fluid pressure. $J$ Neurol Neurosurg Psychiat 1970, 33: 387-397.

26. Martins, A.N., Kobrine, A.I. \& Larson, D.F. Pressure in thesagittal sinus during intracranial hypertension in man. $\sqrt{\omega}$ Neurosurg 1974, 40: 603-608.

\title{
Parathyroid hormone-related protein as a tumour marker in humoral hypercalcaemia associated with occult malignancy
}

\author{
A.C.J. Hutchesson, F. Dunne ${ }^{1}$, N.J. Bundred ${ }^{2}$, H. Gee ${ }^{3}$ and W.A. Ratcliffe ${ }^{4}$
}

Departments of Clinical Chemistry, ${ }^{2}$ Surgery and ${ }^{3}$ Obstetrics and Gynaecology, Selly Oak Hospital,

Birmingham, and ${ }^{1}$ Department of Medicine and ${ }^{4}$ Wolfson Research Laboratories, Queen Elizabeth Medical Centre, Birmingham, UK

\begin{abstract}
Summary: The tumour-derived factor PTH-related protein (PTHRP) is the primary humoral factor responsible for hypercalcaemia in patients with solid tumours. In a woman presenting with anaemia and hypercalcaemia, the finding of raised plasma PTHRP and undetectable serum PTH concentrations led to further investigations and the subsequent identification of a uterine tumour. No evidence of tumour spread was found at operation, and removal of the tumour resulted in normalization of both serum calcium and plasma PTHRP. Expression of PTHRP by the tumour was shown by immunohistochemistry and in situ hybridization. We conclude that the identification of an occult tumour in a patient with hypercalcaemia and raised plasma PTHRP provides evidence of the diagnostic utility of PTHRP immunoassays in the investigation of patients with hypercalcaemia and suspected malignancy.
\end{abstract}

\section{Introduction}

Hypercalcaemia is a common biochemical complication in patients with both solid and haematological malignancies. In the case of solid

Correspondence: A.C.J. Hutchesson, M.R.C.P., Department of Clinical Chemistry, East Birmingham Hospital, Bordesley Green East, Birmingham B9 2ST, UK.

Accepted: 11 January 1993 tumours, there is overwhelming evidence that the tumour-derived factor parathyroid hormone- $\mathcal{O}$ related protein (PTHRP) is an important humoralo mediator of hypercalcaemia, ${ }^{1}$ and is elevated in the ${ }_{\overparen{C}}$ plasma of the majority of hypercalcaemic $\stackrel{\text { ? }}{?}$ patients. ${ }^{2,3}$ Here we report a patient identified 0 during an assessment of the clinical roles of two-site $\frac{\vec{P}}{\mathbb{D}}$ immunoradiometric assays (IRMA) for para- $\stackrel{\mathbb{Q}}{\mathbb{Q}}$ thyroid hormone (PTH) and PTHRP, ${ }^{4}$ in whom $\stackrel{\mathbb{Q}}{\stackrel{Q}{2}}$ 